\title{
Is tidal expiratory flow limitation predictive of sleep-related disorders in the elderly?
}

\author{
M. Guillot*, , F. Costes", E. Sforza", D. Maudoux*, L. Bertoletti*, \\ J.C. Barthélémy ${ }^{\#}$ and F. Roche ${ }^{\#}$
}

ABSTRACT: Sleep-related disorders represent an important health burden and their prevalence increases with age. In patients with snoring or sleepiness, the presence of expiratory flow limitation (EFL), determined via the negative expiratory pressure (NEP) method, is related to the apnoea/hypopnoea index (AHI). In this study, we examined whether EFL can be used to predict obstructive sleep apnoea syndrome (OSAS) in healthy asymptomatic older subjects.

A group of 72 -yr-old subjects ( $n=448,44 \%$ males) with a mean body mass index of $25.5 \pm 3.8 \mathrm{~kg} \cdot \mathrm{m}^{-2}$ were examined. All subjects underwent spirometry, NEP $\left(-5 \mathrm{cmH}_{2} \mathrm{O}\right.$, sitting position) and ventilatory polygraphy (VP).

Spirometry was within normal values in $88 \%$ of the group and EFL was present in $143(32 \%)$ subjects with a higher prevalence in females (89 out of 249 versus 54 out of 199 in females and males, respectively). VP showed an $A H I<15 h^{-1}$ in 238 subjects (53\%) and OSAS with an AHI $\geqslant 15 \mathrm{~h}^{-1}$ in $47 \%$. EFL was found in $15 \%$ of subjects with OSAS. Consequently, EFL had low sensitivity and specificity in the prediction of OSAS (31.4\% and $67.7 \%$, respectively).

We conclude that the prevalence of EFL is elevated in healthy older subjects and cannot be used to predict the presence of sleep-related disorders in an older population.

\section{KEYWORDS: Age, airflow limitation, obstructive sleep apnoea}

leep-related disorders, and especially obstructive sleep apnoea syndrome (OSAS), represent a major public health problem. Its prevalence increases with age [1] and OSAS is associated with cardiovascular morbidity, which may be prevented by adequate diagnosis and treatment [2]. In a previous epidemiological examination study, we found a high rate of unsuspected sleep-related disorders in a 65-yr-old healthy cohort [3].

OSAS diagnosis relies on polysomnography, which is both cost- and time-consuming, and so is currently used only for symptomatic patients. Other screening methods are available. Pulse oximetry is only useful for screening night desaturation. Ventilatory polygraphy (VP) represents an alternative method to polysomnography, although it does not enable sleep architecture to be studied. VP is currently considered to be a valuable tool for screening.

Several studies have emphasised that upper airway collapsibility, one of the mechanisms responsible for OSAS, could be revealed via the negative expiratory pressure (NEP) method, demonstrating that a transient decrease in expiratory flows is provoked by the airway depression. Previous studies have suggested that the presence of an expiratory flow limitation (EFL) revealed by NEP could predict sleep apnoea in selected patients but this relationship has never been studied in a large group of asymptomatic subjects. The NEP technique consists of applying a negative pressure during expiration, which increases the transpulmonary pressure and, in turn, the expiratory flow [4]. On the contrary, an EFL is evidenced by no change or a decrease of expiratory flow with NEP, which represents an extra- or intrathoracic obstruction of the airways. Typical examples of a flowvolume curve with NEP are given in figure 1.

Anatomical structures and neuromuscular control are implicated in the patency of the upper airways. They vary within the respiratory cycle, with sex and sleep state, leading to change in the cross sectional area of the upper airway. These parameters influence the upper airways closing pressure, which participates in the onset of apnoea or hypopnoea. The airway collapsibility seems to be more marked in older subjects due to decreased motor control of the upper airway and changes in the bony structures secondary to edentulism $[5,6]$. The link between EFL and OSAS has been demonstrated in snorers and symptomatic middleaged patients [7-11]. DE BISSCHOP et al. [12] found
AFFILIATIONS

* Service de Pneumologie et d'Oncologie Thoracique, CHU St Etienne, and

${ }^{\#}$ Service de Physiologie Clinique et de l'Exercice, CHU St Etienne, Faculté de Médecine J Lisfranc, EA SNA-EPIS, Université Jean Monnet, PRES de Lyon, France.

CORRESPONDENCE

F. Costes

Service de Physiologie Clinique et de l'Exercice

CHU St Etienne

42055 St Etienne cedex 2

France

E-mail: frederic.costes@

chu-st-etienne.fr

Received:

May 132009

Accepted after revision:

March 222010

First published online:

April 222010 
a high prevalence of EFL in elderly (up to $50 \%$ in females) healthy subjects, which increases with age. This could be explained by the change in age-related thoracopulmonary mechanics, leading older subjects to breathe at a lower pulmonary volume. Therefore, the physiological reduction in expiratory flow in the elderly could reduce the sensitivity and specificity of EFL used in the screening of OSAS. The question remains as to whether EFL could be predictive of sleep-related disorders in asymptomatic and older subjects.

The objectives of this study were therefore two-fold: to confirm the high prevalence of EFL in the elderly and to determine whether EFL could be used as a screening method for OSAS diagnosis.

\section{SUBJECTS AND METHODS \\ Subjects}

The subjects enrolled in this study had already participated in our PROOF (Prognostic Indicator of Cardiovascular and Cerebrovascular Events) cohort study. Briefly, the subjects were recruited via the electoral rolls from the inhabitants of the city of St Etienne, France and were assessed for autonomic nervous system activity, sleep-related disorders and the occurrence of cardiovascular events during a 7-yr follow-up. The description of the primary end-points and the characteristics of the population have been published elsewhere [3].

During the last examination cycle (April 2006 to June 2008), when the subjects were then aged 72 yrs, we additionally investigated lung function and EFL using the NEP technique. We also measured body mass index (BMI) and neck circumference. Sleepiness was categorised using the Epworth Sleepiness Scale; respiratory symptoms and smoking history were assessed by questionnaire.

In a subgroup of 26 subjects, we recorded VP, and performed spirometry and NEP 2 yrs later. They were selected from severe OSAS $(n=6)$ and moderate OSAS $(n=20)$ subjects.

The PROOF study was approved by our local ethics committee (CPP Rhône-Alpes Loire, France) and all subjects gave their written informed consent before participating.

\section{Methods}

Each subject underwent pulmonary function tests and VP on two consecutive days.

\section{Lung function tests}

Maximal flow-volume curves were performed in accordance with European Respiratory Society recommendations, in a sitting position, and the best of three reproducible assays was recorded. The spirometer (Vmax SensorMedics, Yorba Linda, CA, USA) was calibrated with a 3-L syringe before every series of measurements. All measurements were compared to predicted equations [13].

\section{Expiratory flow limitation}

EFL was investigated using the NEP technique (Hypair; Medisoft, Dinan, Belgium) in the sitting position. In the additional group of 26 subjects, NEP was applied in both sitting and supine position. The expiratory flows were compared during spontaneous breathing and with NEP, applying a $5 \mathrm{cmH}_{2} \mathrm{O}$ depression at the mouth. The negative pressure was applied by a Venturi device connected to a pneumotachograph. The principle of NEP is based on increase in pressure gradient between the alveoli and the mouth, which should increase expiratory flow in the absence of airflow limitation. The degree of flow limitation was assessed as the percentage of tidal volume $(V \mathrm{~T})$ where expiratory flows did not increase compared with the spontaneous breath [14]. This was automatically computed by the machine and was not modified by the investigators.

Tidal flow-volume curves were eliminated if they differed by $>10 \%$ from the preceding spontaneous $V \mathrm{~T}$. The average percentage of $V \mathrm{~T}$ flow-limited was calculated from five NEP $V \mathrm{~T}$ and EFL was retained when at least $20 \%$ of VT was flow limited (EFL+).

All measurements were performed by three investigators (M. Guillot, F. Costes and L. Bertoletti), who were blinded to the results of the sleep study.

\section{Sleep study}

Details of the VP system and the methodology used have been published elsewhere $[15,16]$. Briefly, the VP (HypnoPTT, Tyco
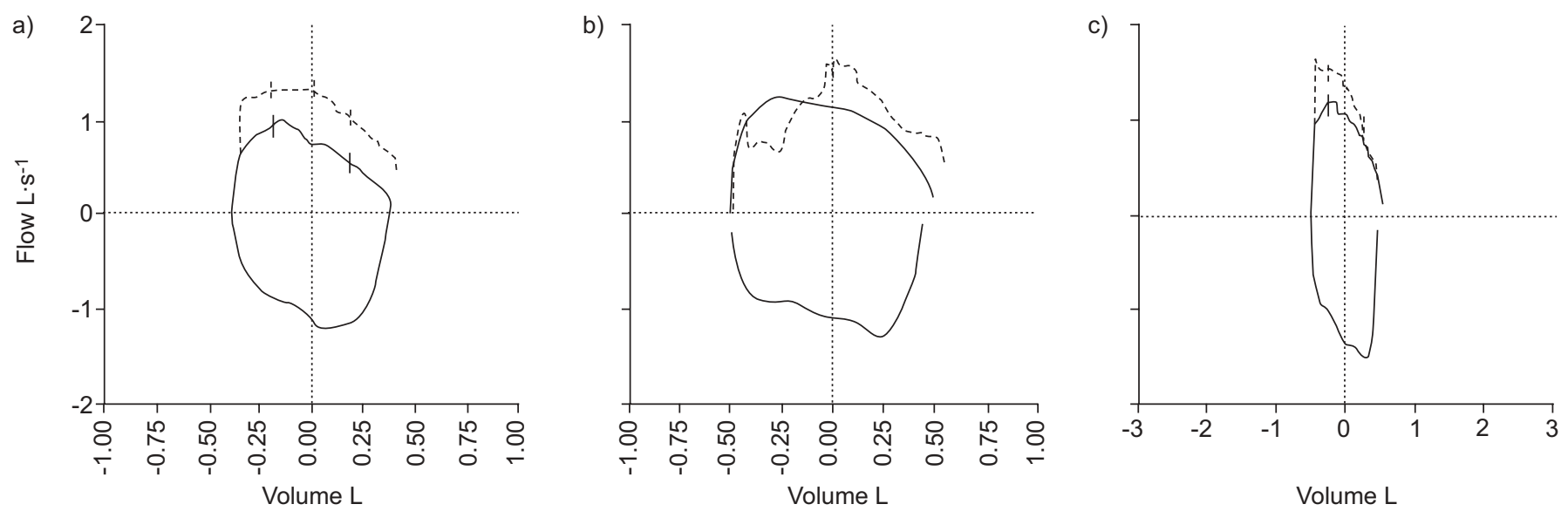

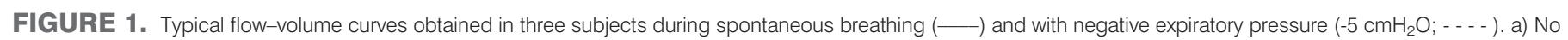

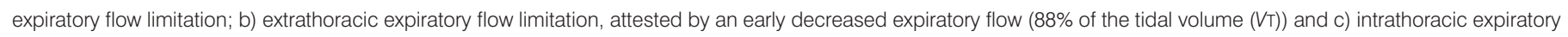
flow limitation, attested by an end-expiratory decrease of the expiratory flow (22\% of VT). 
Healthcare, Puritan Bennett, CA, USA) recorded ECG tracings (one lead), pulse oximetry (sampling rate: $1 \mathrm{~Hz}$, minimal time duration to define an oxyhaemoglobin desaturation event: $10 \mathrm{~s})$, rib cage excursions (transthoracic impedance), body position and nasal pressure for measurement of ventilation. All the recordings were made overnight, at home, on the night before or after the in-hospital respiratory evaluation. A recording duration of $\geqslant 5 \mathrm{~h}$ was required to validate the sleep study. All the recordings were validated visually and manually scored for apnoea/hypopnoea and upper airway high-resistance events by blind investigators. Apnoea and hypopnoea events were defined according to previously published guidelines [17] and an oxyhaemoglobin desaturation threshold $>3 \%$ was chosen. The apnoea/hypopnoea index (number of apnoea and/or hypopnoea events per hour of sleep; AHI), and the oxyhaemoglobin desaturation index (number of desaturations per hour in bed) were calculated. We also evaluated the mean arterial oxygen saturation $\left(\mathrm{Sa}, \mathrm{O}_{2}\right)$, the $\%$ of recording time below $90 \%$ and the minimal value recorded during sleep (nadir $\mathrm{Sa}_{2} \mathrm{O}_{2}$ ), as indices of nocturnal hypoxaemia. OSAS was retained when $\geqslant 50 \%$ of events were obstructive $[18,19]$. In the same way, we separated the subjects according to the predominance of hypopnoeas ( $>50 \%$ of total events) or of apnoeas.

From previously reported data an obstructive AHI $\geqslant 15$ is considered to be diagnostic of OSAS in the elderly [20, 21]. Cases were defined as moderate or severe with an AHI 15-30 or $>30$, respectively.

All sleep studies were analysed by the same investigator ( $\mathrm{F}$. Roche).

\section{Statistical analysis}

Results are expressed as mean \pm SD. We compared anthropometric and spirometric values of the subjects with EFL (EFL+) or without EFL (EFL-), and subjects with or without OSAS using unpaired t-tests. The prevalence of EFL in different subgroups of subjects was compared by Chi-squared (Fisher's exact test).

We calculated the sensitivity, the specificity, the positive predictive value (PPV), the negative predictive value (NPV), the false-positive and false-negative rates of EFL for predicting OSAS using a threshold for AHI $\geqslant 15$.

We next added high Epworth scale scores $(>10)$ to EFL for predicting OSAS.

All the analyses were carried out using the Statview 5.0 software (SAS Institute Inc., CARY, NC, USA).

\section{RESULTS}

A total of 448 subjects (250 (56\%) females and 198 (44\%) males) were included. Their characteristics are given in table 1 . In general, they were of normal weight: only $45(10 \%)$ were obese $\left(\right.$ BMI $\left.>30 \mathrm{~kg} \cdot \mathrm{m}^{-2}\right)$, although this subset of subjects had similar $\mathrm{BMI}$ and neck circumference measurements to the rest of the study population.

The Epworth score was within normal ranges $(5.0 \pm 3.6$ for females and $6.7 \pm 3.8$ for males) with 57 (12.7\%) subjects considered as sleepy with an Epworth score of more $>10$.

\section{Spirometry and NEP results}

Spirometry was normal in 396 (88\%) subjects. 42 (9\%) patients showed an obstructive pattern and a restrictive pattern was seen in $10(2 \%)$.

The percentage of $V \mathrm{~T}$ flow-limited tended to be higher in females than in males $(21.0 \pm 27.3 \%$ versus $16.3 \pm 26.7 \%$; $\mathrm{p}=0.06)$. The presence or absence of bronchial obstruction did not influence the \% of $V$ T flow-limited $(21.4 \pm 25.8 \%$ versus $18.2 \pm 27.0 \%, p=0.2)$.

Considering the $20 \% \mathrm{~V}_{\mathrm{T}}$ flow-limited cut-off, EFL was present in 143 subjects $(32 \%)$ and tended to be more frequent in females $(62 \%$ versus $38 \%$; $\mathrm{p}=0.05)$.

EFL was not correlated to BMI or neck circumference.

In the additional subgroup of 26 subjects, spirometry was normal in all but two (obstructive pattern), and stable compared with the previous measurements. Results of VP were also unchanged (AHI >30, $n=6$, and AHI >15, $n=20$ ). In seven subjects $(26.9 \%)$, EFL was considered in supine position $(54.5 \%$ of $V$ T flow-limited) while it was absent in sitting position. Among them OSAS was present in only two. Therefore, the combination of EFL measurement in both supine and sitting

\begin{tabular}{|c|c|c|c|c|}
\hline \multirow[t]{2}{*}{ TABLE 1} & \multicolumn{4}{|c|}{$\begin{array}{l}\text { Characteristics of the population with their results } \\
\text { for spirometry and nocturnal ventilatory } \\
\text { polygraphy }\end{array}$} \\
\hline & & All subjects & Males & Females \\
\hline \multicolumn{2}{|l|}{ Subjects } & 448 & $199(44.4)$ & $249(55.6)$ \\
\hline \multicolumn{2}{|l|}{ Age yrs } & $72 \pm 2$ & $72 \pm 1$ & $72 \pm 2$ \\
\hline \multicolumn{2}{|l|}{ BMI $\mathbf{k g} \cdot \mathrm{m}^{-2}$} & $25.5 \pm 3.8$ & $25.8 \pm 3.2$ & $25.2 \pm 4.2$ \\
\hline \multicolumn{2}{|c|}{ Neck circumference $\mathrm{cm}$} & $36.8 \pm 3.8$ & $39.7 \pm 3.0$ & $34.5 \pm 2.7$ \\
\hline \multicolumn{2}{|c|}{ Epworth sleepiness score } & $5.7 \pm 3.9$ & $6.7 \pm 3.8$ & $5.0 \pm 3.6$ \\
\hline \multicolumn{5}{|c|}{ Pulmonary function tests } \\
\hline \multicolumn{2}{|c|}{ FEV $1 \%$ pred } & $102 \pm 17.3$ & $99.8 \pm 17.8$ & $103.8 \pm 16.7$ \\
\hline \multicolumn{2}{|c|}{ FVC \% pred } & $108.8 \pm 17.5$ & $103.4 \pm 16.5$ & $113.0 \pm 17.1$ \\
\hline \multicolumn{2}{|c|}{ PEF \% pred } & $98.3 \pm 20.6$ & $103.7 \pm 21.8$ & $93.9 \pm 18.4$ \\
\hline \multicolumn{2}{|c|}{ FEF25-75\% \% pred } & $71.2 \pm 26.3$ & $74.4 \pm 27.3$ & $68.5 \pm 25.3$ \\
\hline \multicolumn{5}{|c|}{ Ventilatory polygraphy } \\
\hline \multicolumn{2}{|c|}{ Total sleep time min } & $442.1 \pm 111.4$ & $424.4 \pm 115.8$ & $456.2 \pm 105.8$ \\
\hline \multicolumn{2}{|c|}{ Average $\mathrm{Sp}, \mathrm{O}_{2} \%$} & $95.3 \pm 1.6$ & $95.4 \pm 1.6$ & $95.2 \pm 1.5$ \\
\hline \multicolumn{2}{|c|}{ Minimum $\mathrm{Sp}, \mathrm{O}_{2} \%$} & $89.3 \pm 4.4$ & $89.0 \pm 4.6$ & $90.0 \pm 4.2$ \\
\hline \multicolumn{2}{|c|}{ ODI events $\cdot h^{-1}$} & $9.7 \pm 9.7$ & $12.3 \pm 11.3$ & $7.7 \pm 7.8$ \\
\hline \multicolumn{2}{|c|}{$\mathrm{AHI}$ events $\cdot \mathrm{h}^{-1}$} & $17.7 \pm 14.3$ & $21.6 \pm 15.6$ & $14.6 \pm 12.3$ \\
\hline \multicolumn{2}{|c|}{$\mathrm{IA}>\mathrm{IH}$} & $63(30)$ & $41(19.5)$ & $22(10.5)$ \\
\hline \multicolumn{2}{|c|}{ Dorsal events } & $128(63.4)$ & $67(62.6)$ & $61(64.2)$ \\
\hline
\end{tabular}

Data are presented as $\mathrm{n}, \mathrm{n}(\%)$ or mean $\pm \mathrm{SD}$. Oxyhaemoglobin desaturation index (ODI) retained as a $3 \%$ decrease in arterial oxygen saturation measured by pulse oximetry $\left(\mathrm{Sp}, \mathrm{O}_{2}\right)$. Apnoea/hypopnoea index $(\mathrm{AHI})$ recorded with ventilatory polygraphy. $\mathrm{IA}>\mathrm{IH}$ refers to apnoea index superior to hypopnoea index. Dorsal events represent the number of subjects presenting a majority of events ( $>50 \%$ of total events) in dorsal position compared to lateral one. BMI: body mass index; FEV1: forced expiratory flow in $1 \mathrm{~s}$; \% pred: \% predicted; FVC: forced vital capacity; PEF peak expiratory flow; FEF25-75\%: forced expiratory flow at $25-75 \%$ of FVC. 
position did not increase the predictive value of NEP for OSAS in this selected group of subjects.

\section{Results of ventilatory polygraphy}

$238(53 \%)$ subjects had no OSAS (153 females and 83 males). $135(30 \%)$ subjects had moderate OSAS (69 females and 66 males) and 75 subjects $(17 \%)$ had an AHI $\geqslant 30 \mathrm{~h}^{-1}$ (26 females and 49 males) (table 1).

All the subjects had an obstructive sleep apnoea syndrome considering the predominance of obstructive events. In all but one eliminating central events did not change the AHI in a way that the diagnosis of the subjects was modified.

Among the subjects with an $\mathrm{AHI} \geqslant 15 \mathrm{~h}^{-1}$, only 25 (11.9\%) were receiving treatment (hypnotics, muscle relaxants, morphine derivatives and anxiolytics) that may have altered upper airway tone and thus the NEP measurements.

\section{EFL versus VP}

When analysing both the NEP and VP (table 2) of the 143 EFL+ subjects, $77(53.8 \%)$ were found to have an AHI <15, $41(28.7 \%)$ were in the $15 \leqslant \mathrm{AHI}<30$ band and $25(17.5 \%)$ subjects had an $\mathrm{AHI} \geqslant 30$.

This gives a weak but nonsignificant relationship as well as a poor predictive value: sensitivity was $33 \%$ and $30 \%$ for $\mathrm{AHI} \geqslant 30$ and $15 \leqslant \mathrm{AHI}<30$ respectively, and PPV was $17.5 \%$ and $28.7 \%$ for the presence of EFL in the detection of an OSAS (table 3).

Among the 305 EFL- subjects, 161 subjects (53\%) had an AHI $<15$, and 144 subjects $(32 \%)$ an $A H I \geqslant 15$. Sensitivity was improved but the PPV remained low (table 3 ).

These statistical results did not vary with sex.

Most of the subjects were hypopnoeic considering the predominance of hypopnoeas (147 out of 210, 70\%, with 72 males and 97 females). Only 44 (29.9\%) of them were EFL+ and this percentage was similar for males and females $(27.8 \%$ and $24.8 \%$, respectively). The prevalence of EFL+ was similar in the hypopnoea group compared to the apnoea group $(p=0.9)$.

Obstructive events were more frequent in dorsal than in lateral position (62.6\% in males and $64.2 \%$ in females). However, only $28.9 \%$ of the subjects in the dorsal subgroup were EFL+ $(31.3 \%$ in males and $26.2 \%$ in females, $p=0.09$ and 0.9 , respectively).

\begin{tabular}{|c|c|c|c|c|c|c|}
\hline \multirow[t]{3}{*}{ TABLE 2} & \multicolumn{6}{|c|}{$\begin{array}{l}\text { Presence of expiratory flow limitation (EFL) in } \\
\text { relation to the apnoea/hypopnoea index (AHI) }\end{array}$} \\
\hline & \multicolumn{2}{|c|}{ All subjects } & \multicolumn{2}{|c|}{ Males } & \multicolumn{2}{|c|}{ Females } \\
\hline & EFL+ & EFL- & EFL+ & EFL- & EFL+ & EFL- \\
\hline $\mathrm{AHI}<15$ & 77 (17.2) & $161(35.9)$ & $20(10.1)$ & 64 & 57 (22.9) & 97 \\
\hline $15 \leqslant \mathrm{AHI}<\mathbf{3 0}$ & 41 (9.2) & 94 (21.0) & $16(8.0)$ & 50 & $25(10.0)$ & 44 \\
\hline$A H I \geqslant 30$ & $25(5.6)$ & $50(11.2)$ & $18(9.0)$ & 31 & $7(2.8)$ & 19 \\
\hline
\end{tabular}

Considering the 57 sleepy subjects, 25 had an AHI $<15$ (43.9\% of this subset) and 10 subjects had an $\mathrm{AHI} \geqslant 30$ (17.5\%). The Epworth Sleepiness Score was, therefore, not a good predictor of OSAS: sensitivity and PPV were low (15.2\% and $56.1 \%$, respectively, for $\mathrm{AHI} \geqslant 15$ and $13.3 \%$ and $17.5 \%$ for $\mathrm{AHI} \geqslant 30$ ).

In order to assess whether the presence of clinical complaints such as sleepiness could be used to define the presence of sleep-disordered breathing we examined the 20 subjects having both an EFL and an Epworth score $>10$ (4.5\% of the total and $9.5 \%$ of the OSAS subjects). Only 13 subjects had an $\mathrm{AHI} \geqslant 15$, leading to very low sensitivity and PPV $(7.6 \%$ and $53.3 \%$, respectively). Similar results were obtained in the three subjects with $\mathrm{AHI} \geqslant 30(9.3 \%$ and $23.3 \%$ for sensitivity and PPV respectively). Predictive value was not better for the 270 non-somnolent and EFL- subjects, of whom 143 had no OSAS.

\section{DISCUSSION}

In this study, we did not find any relationship between the occurrence of EFL, as measured with NEP, performed in awake subjects in a seated position and with a $5 \mathrm{cmH}_{2} \mathrm{O}$ depression, and sleep-related disorders in our population of older subjects, leading to the conclusion that NEP is not suitable for epidemiological screening of OSAS. However, we did confirm that the prevalence of EFL is elevated in elderly subjects (one-third of the subjects), especially in females.

\section{Relationship between NEP and OSAS}

The characteristics of our population corresponded to that of the usual population of this age range with more females than males and a similar sex ratio for the prevalence of OSAS [3].

Given the high prevalence of sleep-related disorders we noted in this cohort, it seemed interesting to look for a relationship between sleep-related disorders and EFL. Indeed, several studies have emphasised that the NEP technique was able to detect patients with OSAS through the visualisation of a transient decrease in expiratory flow at the onset of negative pressure. This phenomenon was uncommon in the subjects of the present study. Moreover, we found a low predictive value of NEP for the detection of sleep-related disorders.

Although one study found a limited usefulness of NEP for the detection of OSAS in a small group of apnoeic patients and snorers [22], other studies demonstrated a higher incidence of EFL with NEP in OSAS patients [7-11, 23].

\begin{tabular}{|c|c|c|c|c|}
\hline TABLE 3 & $\begin{array}{l}\text { diction of } \\
\text { n expiratc }\end{array}$ & $\begin{array}{l}\text { structive } \\
\text { flow limit }\end{array}$ & $\begin{array}{l}\text { eep apnoea } \\
\text { tion }\end{array}$ & yndrome \\
\hline & $\mathrm{AHI}<15$ & $A H I \geqslant 15$ & $15 \leqslant \mathrm{AHI}<30$ & $\mathrm{AHI} \geqslant 30$ \\
\hline Sensitivity \% & 67.7 & 31.4 & 30.4 & 33.3 \\
\hline Specificity \% & 31.4 & 67.7 & 67.2 & 68.4 \\
\hline PPV \% & 52.8 & 46.2 & 28.7 & 17.5 \\
\hline NPV \% & 46.2 & 52.8 & 69.2 & 83.6 \\
\hline False-positive \% & 47.2 & 53.9 & 71.3 & 82.5 \\
\hline False-negative \% & 53.9 & 47.2 & 31.0 & 16.4 \\
\hline
\end{tabular}


In a large sample of middle-aged patients with clinically suspected OSAS or with snoring, VAN MEERHAEGHE et al. [8] found a moderate sensitivity and specificity for predicting OSAS and the relationship between EFL and AHI was more significant in the supine than the sitting position. Using receiver operating characteristic analysis, these authors defined a cut-off value of $27.5 \%$ of $V$ T flow-limited to predict an increase in AHI. In this study, we arbitrarily fixed a cut off value of $20 \%$. This cut-off was chosen from our clinical experience, which has demonstrated the inconstant presence of EFL at different NEP breaths below 20\% $V$ T flow-limited. Nevertheless, reanalysing the data with a $27.5 \%$ cut-off value for EFL did not improve the sensitivity/specificity of the NEP technique. Therefore, our definition of flow-limited subjects could not explain our negative results.

In most studies EFL has been found to be more common when the patients were studied in the supine than in the seated position. For practical reasons, it was not possible for us to explore EFL in both positions, and we acknowledge that this is an important limitation in our study. However, in an additional subgroup of 26 subjects explored with NEP in sitting and supine position, we found that considering EFL in supine position did not influence the prediction of OSAS. Although we can not draw definite conclusions from this small subgroup of subjects, this result suggests that the experimental conditions of EFL measurement could not solely explain the lack of prediction of OSAS by the NEP method.

\section{Discrepancies between our study and previous reports}

An increased occurrence of EFL has been reported in various studies [7, 10, 23] and it has been ascribed to upper airway collapsibility in OSAS patients. Several differences between these studies and ours should be mentioned. First, the former included patients attending a sleep clinic, thus with a clinical suspicion of OSAS or snorers. We can surmise therefore that these subjects had more severe or more long-lasting sleep disorders than those in our epidemiological study. Secondly, most of the patients included were younger than ours and were overweight or obese, whereas only $10 \%$ of our subjects had a BMI $>30 \mathrm{~kg} \cdot \mathrm{m}^{-2}$. However, BAYDUR et al. [24] found that EFL was rare in obese patients and that its incidence was as common as in healthy controls. Thus, the difference in weight cannot explain the discrepancy between our results and those in previous studies.

The importance of EFL could be expressed in a more complex, and maybe in a more sensitive way, than in our study. TAMISIER et al. [9] calculated the area under the curve with NEP compared to the control condition and reported that a value of $<160 \%$ and $180 \%$ for -5 and $-10 \mathrm{cmH}_{2} \mathrm{O}$, respectively, identified patients with OSAS. Alternatively, RouATBI et al. [11] recorded oscillations on the flow-volume curve and their numbers increased significantly in OSAS patients and snorers. It seems rather difficult to quantify this in a clinical setting and to make the number of oscillations a suitable index for sleep-related disorder detection.

Whatever the differences between our study and others, it appears unlikely that the absence of a relationship between EFL and sleep-related disorders can be explained solely by technical or methodological reasons.

\section{Limitation of our study}

The type of sleep events could have influenced the presence or absence of EFL. NEP is supposed to increase the upper airway collapsibility, so we can suspect that EFL would be more closely correlated to hypopnoea than to apnoea. However, our results do not support this, since the percentage of EFL was similar according to the predominance of hypopnoeas or apnoeas, without any influence of sex.

Upper airway stability also varies with the position of the subjects, with the events being more frequent in the dorsal than in the lateral position. Although we confirm the predominance of events in the dorsal position, it did not influence the presence or absence of EFL. These results suggest that the mechanism by which obstructive events occurred differs during sleep and during the application of NEP.

We did not control the position of the neck during the application of the NEP. Indeed, WALSH et al. [25] found that head flexion increased the pharyngeal critical closing pressure ( $\left.P_{\text {crit }}\right)$ and thus promoted the collapsibility of the upper airway. This could partly explain the high prevalence of EFL+, but not the difference between males and females.

\section{Prevalence of EFL in the elderly}

We found an EFL in about one-third of the subjects, with a tendency to a higher prevalence in females. We can be confident in this result, since the subjects in the PROOF cohort were not selected on the basis of respiratory complaints. Moreover, characteristics of our subgroup of 448 subjects did not differ from those of the whole cohort (sex ratio, prevalence of EFL+ and OSAS, BMI, and percentage of airway obstruction). We found that EFL was not influenced by the existence of respiratory symptoms evoking asthma or chronic obstructive pulmonary disease, by the smoking habits, by the New York Heart Association score or by the presence of obstruction of the airways assessed by forced expiratory volume in $1 \mathrm{~s} /$ forced vital capacity $(\mathrm{FEV} 1 / \mathrm{FVC})$ ratio $<0.7$. These parameters cannot also explain the difference in prevalence of EFL with sex.

Surprisingly, we found a higher prevalence of EFL among males with a low FVC ( $<80 \%$ predicted value on spirometry) but not in females. We confirm the results of DE BISSCHOP et al. [12] concerning the elevated prevalence of EFL in elderly, especially in females, but we have no consistent explanation for the difference according to sex. This deserves further study.

\section{Physiopathology of OSAS in the elderly}

The presence of obstructive sleep apnoea is partly related to a greater $P_{\text {crit, }}$ which reflects the increase in upper airway collapsibility [26-28]. EILKERMANN et al. [29] showed that increasing age was correlated with both pharyngeal collapsibility and an increase in pharyngeal resistance during sleep. Ageing is characterised by increased Pcrit and upper airway resistance [28], predisposing the subject to facilitated upper airway closures. Thus, the lack of correlation between an EFL under NEP and the presence of OSAS appears puzzling and suggests that factors other than upper airway collapsibility must also be responsible for the high prevalence of obstructive sleep apnoea in the elderly. The absence of correlation between upper airway morphology measured by computed tomography and OSAS has been demonstrated by MAYER et al. [30]. We 
extend this previous result, and demonstrate that, in older subjects, NEP is neither sensitive nor specific enough to explore dynamic upper airway compliance.

The question remains as to why these subjects presented a high incidence of EFL when a low level of NEP was applied at the mouth. Our study was not designed to detect an increasing prevalence with age, as showed by DE BissCHOP et al. [12]. One cause could be facilitated upper airway collapse caused by slackening of the soft tissue with age, as has already been demonstrated with the decline in tongue strength [31]. A second cause could be that older subjects could breathe at a lower volume, close to the residual volume, and the tidal expiratory flows would result in encroachment of the maximal flow-volume loop. This change in ventilatory mechanics could explain airflow limitation with NEP; thus, EFL with NEP would reflect an adaptative strategy for breathing and not a pathological pattern such as an upper airway collapse.

These physiological adaptations with age could explain why EFL with NEP present such a high NEP value in detecting OSAS. From the design and the aim of the study we could not assert that a low functional residual capacity is associated with the presence of EFL and is predominant in females. Conditions during the night are obviously different from those present in our experimental conditions, which would explain why EFL during the day did not correspond to the occurrence of hypopnoeas/apnoeas.

\section{Relationship between OSAS and sleepiness in the elderly}

The characteristics of the subjects studied here, for whom a diagnosis of severe OSAS (AHI $\geqslant 30$ ) was made for $17 \%$ of them, were usual for this age range with normal BMI values and low sleepiness scores. However 25, of the 75 OSAS subjects, including 16 females $(64 \%)$, were on medication that could have influenced sleep or muscular tone (hypnotics, muscle relaxants, morphine derivatives and, anxiolytics). However, even if we exclude these subjects, there is no difference in the statistical analyses for the 423 other subjects. Moreover, in accordance with previous studies, sleepiness evaluated with the Epworth Sleepiness Scale did not allow us to predict the existence of OSAS [1, 32-35]. Furthermore, the combination of OSAS, defined as AHI $\geqslant 15$, and the presence of sleepiness, did not increase the predictive values of the NEP.

\section{Conclusion}

In a large subset of older healthy subjects, a high incidence of sleep-related disorders and EFL were detected using the NEP technique. However, the presence of EFL was not predictive of sleep-related disorders and, consequently, NEP was not found to be suitable for epidemiological screening of OSAS.

\section{CLINICAL TRIAL}

This study is registered with clinical trial identifier number NCT00766584.

\section{STATEMENT OF INTEREST}

None declared.

\section{REFERENCES}

1 Duran J, Esnaola S, Rubio R, et al. Obstructive sleep apneahypopnea and related clinical features in a population-based sample of subjects aged 30 to 70 yr. Am J Respir Crit Care Med 2001; 163: 685-689.

2 Marin JM, Carrizo SJ, Vicente E, et al. Long-term cardiovascular outcomes in men with obstructive sleep apnoea-hypopnoea with or without treatment with continuous positive airway pressure: an observational study. Lancet 2005; 365: 1046-1053.

3 Barthelemy JC, Pichot V, Dauphinot V, et al. Autonomic nervous system activity and decline as prognostic indicators of cardiovascular and cerebrovascular events: the "PROOF" Study. Study design and population sample. Associations with sleep-related breathing disorders: the "SYNAPSE" Study. Neuroepidemiology 2007; 29: 18-28.

4 Koulouris N, Valta P, Lavoie A, et al. A simple method to detect expiratory flow limitation during spontneous breathing. Eur Respir J 1995; 8: 306-313.

5 Pack AI, Silage DA, Millman RP, et al. Spectral analysis of ventilation in elderly subjects awake and asleep. J Appl Physiol 1988; 64: 1257-1267.

6 Riha RL, Brander P, Vennelle M, et al. A cephalometric comparison of patients with the sleep apnea/hypopnea syndrome and their siblings. Sleep 2005; 28: 315-320.

7 Tantucci C, Duguet A, Ferretti A, et al. Effect of negative expiratory pressure on respiratory system flow resistance in awake snorers and nonsnorers. J Appl Physiol 1999; 87: 969-976.

8 Van Meerhaeghe A, Delpire P, Stenuit P, et al. Operating characteristics of the negative expiratory pressure technique in predicting obstructive sleep apnoea syndrome in snoring patients. Thorax 2004; 59: 883-888.

9 Tamisier R, Wuyam B, Nicolle I, et al. Awake flow limitation with negative expiratory pressure in sleep disordered breathing. Sleep Med 2005; 6: 205-213.

10 Verin E, Tardif C, Portier F, et al. Evidence for expiratory flow limitation of extrathoracic origin in patients with obstructive sleep apnoea. Thorax 2002; 57: 423-428.

11 Rouatbi S, Tabka Z, Dogui M, et al. Negative expiratory rressure (NEP) parameters can predict obstructive sleep apnea syndrome in snoring patients. Lung 2009; 187: 23-28.

12 de Bisschop C, Marty ML, Tessier JF, et al. Expiratory flow limitation and obstruction in the elderly. Eur Respir J 2005; 26: 594-601.

13 Quanjer PH, Tammeling GJ, Cotes JE, et al. Lung volumes and forced ventilatory flows. Report Working Party Standardization of Lung Function Tests European Community for Steel and Coal. Eur Respir J 1993; 6: Suppl. 16, 5-40.

14 Calverley PM, Koulouris NG. Flow limitation and dynamic hyperinflation: key concepts in modern respiratory physiology. Eur Respir J 2005; 25: 186-199.

15 Ancoli-Israel S, Kripke DF, Mason W, et al. Comparisons of home sleep recordings and polysomnograms in older adults with sleep disorders. Sleep 1981; 4: 283-291.

16 Series F, Marc I. Nasal pressure recording in the diagnosis of sleep apnoea hypopnoea syndrome. Thorax 1999; 54: 506-510.

17 Sleep-related breathing disorders in adults: recommendations for syndrome definition and measurement techniques in clinical research. Sleep Med 1999; 22: 667-689.

18 Eckert D, Jordan A, Merchia P, et al. Central sleep apnea: pathophysiology and treatment. Chest 2007; 131: 595-607.

19 Yumino D Bradley T. Central sleep apnea and Cheyne-Stokes respiration. Proc Am Thorac Soc 2008; 5: 226-236.

20 Mant A, Saunders N, Eyland E. Sleep habits and sleep related respiratory disturbance in an older population In: Horne J, et al., eds. Sleep '88. Stuttgart, Gustav Fischer Verlag, 1989; pp. 260-261.

21 International classification of sleep disorders, Edn 2: diagnostic and coding manual. Chicago, American Academy of Sleep Medicine, 2005.

22 Ferretti A, Giampiccolo P, Redolfi S, et al. Upper airway dynamics during negative expiratory pressure in apneic and non-apneic awake snorers. Respir Res 2006; 30: 54. 
23 Liistro G, Veriter C, Dury M, et al. Expiratory flow limitation in awake sleep-disordered breathing subjects. Eur Respir J 1999; 14: 185-190.

24 Baydur A, Wilkinson L, Mehdian R, et al. Extrathoracic expiratory flow limitation in obesity and obstructive and restrictive disorders: effects of increasing negative expiratory pressure. Chest 2004; 125 : 98-105.

25 Walsh J H, Maddison KJ, Platt RR, et al. Influence of head extension, flexion, and rotation on collapsibility of the passive upper airway. Sleep 2008; 31: 1440-1447.

26 Sforza E, Petiau C, Weiss T, et al. Pharyngeal critical pressure in patients with obstructive sleep apnea syndrome. Clinical implications. Am J Respir Crit Care Med 1999; 159: 149-157.

27 Boudewyns A, Punjabi N, Van de Heyning PH, et al. Abbreviated method for assessing upper airway function in obstructive sleep apnea. Chest 2000; 118: 1031-1041.

28 Kirkness JP, Schwartz AR, Schneider H, et al. Contribution of male sex, age, and obesity to mechanical instability of the upper airway during sleep. J Appl Physiol 2008; 104: 1618-1624.
29 Eikermann M, Jordan AS, Chamberlin NL, et al. The influence of aging on pharyngeal collapsibility during sleep. Chest 2007; 131: 1702-1709.

30 Mayer P, Pépin J, Bettega G, et al. Relationship between body mass index, age and upper airway measurements in snorers and sleep apnoea patients. Eur Respir J 1996; 9: 1801-1809.

31 Crow HC, Ship JA. Tongue strength and endurance in different aged individuals. J Gerontol A Biol Sci Med Sci 1996; 51: M247-M250.

32 Rosenthal LD, Dolan DC. The Epworth sleepiness scale in the identification of obstructive sleep apnea. J Nerv Ment Dis 2008; 196: 429-31.

33 Roure N, Gomez S, Mediano O, et al. Daytime sleepiness and polysomnography in obstructive sleep apnea patients. Sleep Med 2008; 9: 727-731.

34 Hayashida K, Inoue Y, Chiba S, et al. Factors influencing subjective sleepiness in patients with obstructive sleep apnea syndrome. Psychiatry Clin Neurosci 2007; 61: 558-563.

35 Mediano O, Barcelo A, de la Pena M, et al. Daytime sleepiness and polysomnographic variables in sleep apnoea patients. Eur Respir J 2007; 30: 110-113. 